\title{
Effect of tetracycline treatment regimens on antibiotic resistance gene selection over time in nursery pigs
}

\author{
Kaare Græsbøll', Inge Larsen², Julie Clasen ${ }^{3}$, Anna Camilla Birkegård ${ }^{1}$, Jens Peter Nielsen², \\ Lasse Engbo Christiansen ${ }^{1}$, John Elmerdahl Olsen², Øystein Angen ${ }^{3,4}$ and Anders Folkesson ${ }^{5^{*}}$ id
}

\begin{abstract}
Background: The majority of antimicrobials given during the production of pigs are given to nursery pigs. The influence of antimicrobial use on the levels of antimicrobial resistant (AMR) genes is important to quantify to be able to assess the impact of resistance on the food chain and risk to human and animal health.

Results: This study investigated the response on the levels of nine AMR genes to five different treatment strategies with oxytetracycline, and the dynamics of gene abundance over time by following 1167 pigs from five different farms in Denmark.

The results showed no significant difference between treatments and an increase in abundance for the efflux pump encoding tet( $(A)$ gene and the genes encoding the ribosomal protection proteins tet $(O)$ and tet $(W)$ tetracycline resistant genes following treatment, while tet $(M)$ showed no response to treatment. However, it was also observed that the levels of tet( $(O)$, tet $(W)$, and ermB in some farms would drift more over time compared to a single treatment-course with antibiotic.

Conclusion: This study underlines the large variation in AMR levels under natural conditions and the need for increased investigation of the complex interactions of antimicrobial treatment and other environmental and managerial practices in swine production on AMR gene abundance.
\end{abstract}

Keywords: Oxytetracycline, Resistance genes, qPCR, Nursery pigs

\section{Background}

Antimicrobial resistance (AMR) in bacteria is a growing global health concern that threatens to decrease the effectiveness of infectious disease treatment both in humans and animals [1-5]. Resistance towards antibiotics is an ancient characteristic that presumably coevolved with the evolution of antibiotic producing organisms and is widespread in nature [6-10]. The intensive use of antibiotics in society in general, and in the food production systems in particular, may increase the chance of transmission of antibiotic resistant microorganisms to humans from livestock or the environment

\footnotetext{
* Correspondence: afol@vet.dtu.dk

${ }^{5}$ DTU BioEngineering, Technical University of Denmark, Kongens Lyngby, Denmark

Full list of author information is available at the end of the article
}

through the consumption of food products of animal origin or through water and soil [11-14].

The effect of antimicrobial use in food production on AMR in humans has been difficult to quantify [15-20] and routes and the rates of AMR transmission are not well characterized [21]. Moreover, the impact of AMR on animal health and food production is even less elucidated. A reason for this could be the reliance on culture based methods for detection of pathogens and indicator organisms, since such methods are unable to quantify the AMR gene prevalence in the commensal microflora [21]. Recent technological developments in molecular biology, however, have increased our ability to investigate and quantify the gene content of microbial communities without cultivation. This has enabled us to study to what extent the normal flora is affected by the use of

(c) The Author(s). 2019 Open Access This article is distributed under the terms of the Creative Commons Attribution 4.0 International License (http://creativecommons.org/licenses/by/4.0/), which permits unrestricted use, distribution, and reproduction in any medium, provided you give appropriate credit to the original author(s) and the source, provide a link to the Creative Commons license, and indicate if changes were made. The Creative Commons Public Domain Dedication waiver (http://creativecommons.org/publicdomain/zero/1.0/) applies to the data made available in this article, unless otherwise stated. 
antimicrobials, and to detail the molecular ecology of AMR genes [21-26].

Gastrointestinal bacterial infection is a common disease in many animal production systems and an important incentive for antimicrobial treatment [27-30]. Oral administration of antimicrobials is widely used to control such infections in the pig industry [31-33]. In Denmark, tetracycline has been the most commonly used antimicrobial for oral treatment of gastrointestinal disorders in pigs, such as Lawsonia intracellularis (L.intracellularis) infections [34].

The world organisation for animal health (OIE) recommends clinical trials to evaluate the validity of therapeutic indications and dosage regimens, to protect both animal and human health as well as the environment [35]. The effect of oxytetracycline treatment on faecal shedding of $L$. intracellularis and weight gain in nursery pigs suffering from diarrhoea has recently been investigated in a clinical field trial in Denmark, where the effect of different dosage regimens and administration routes were studied [33, 36]. Here, we study the impact of these different treatment regimens on the prevalence and levels of nine AMR genes $(\operatorname{ermB}, \operatorname{ermF}$, sull, sulII, tet $(A), \operatorname{tet}(B), \operatorname{tet}(\mathrm{M}), \operatorname{tet}(\mathrm{O})$ and tet $(\mathrm{W}))$ which are frequently present in pigs on Danish pig farms $[37,38]$ The aim of the present study was to determine the effect of five different oxytetracycline treatment regimens on a selection of AMR genes in the normal flora in nursery pigs in a randomized clinical field trial.

\section{Results}

\section{Sample collection}

A total of five farms were included in the study, and samples were collected from a total of 1167 ear marked pigs. 240 pigs received batch treatment with High Dose (HD), 241 with Normal Dose (ND) and 224 with Low Dose (LD) of oxytetracycline (OTC). 241 pigs were included in the pen wise treatment group (PW), and 221 in the injection treatment group (IM). Of the 241 pigs in the PW group, 204 received treatment with OTC, and of the 221 pigs in the IM group, 124 received treatment with OTC. The pigs where sampled before treatment with oxytetracycline (T1), two days after end of treatment (T2), and when exiting the nursery stable (T3). Each farm was assigned a stratified random treatment group in sequential batches, where an entire section would be treated in the same way. After a completed batch a new batch would randomly be assigned to the same or a different treatment. Typically, each farm were assigned to every treatment regime three times (ranging from two to four).

\section{Enrichment of tetracycline resistance genes after tetracycline treatment}

We analysed the relative abundance and prevalence of nine individual antibiotic resistance genes in the samples collected at three time points from the five different treatment groups; ermB, ermF, that confers macrolide resistance; sull, sulII conferring resistance towards sulphonamides and $\operatorname{tet}(A), \operatorname{tet}(B), \operatorname{tet}(M), \operatorname{tet}(O)$, and $\operatorname{tet}(W)$ that confers increased resistance towards tetracycline. Five genes $\operatorname{ermB}, \operatorname{ermF}, \operatorname{tet}(M), \operatorname{tet}(O)$, and $\operatorname{tet}(W)$ were always present and was quantified relative to the number of $16 \mathrm{~s}$ RNA genes in the same sample, while four genes, sulI, sulII, tet(A), and tet(B), were only sporadically present and were analysed based on prevalence. Relative quantities and prevalence of genes are presented in Additional file 1: Figure S1, Additional file 2: Figure S2, Additional file 3: Figure S3, Additional file 4: Figure S4, Additional file 5: Figure S5, Additional file 6: Figure S6, Additional file 7: Figure S7.

Figure 1 shows the changes in levels of genes from before treatment to after treatment (T1 to T2), from after treatment to exit of the nursery unit (T2 to T3), and over the entire stay in the nursery unit (T1 to T3). Generally, two genes, ermF and tet $M$ showed the largest variation in how pigs responded to the different treatments, however, no differences were observed in changes for any of the five genes analysed depending on the treatment (dose variation and variation in application).

Furthermore, all pigs originating from one farm were aggregated to visually inspect for changes of each gene in the five different farms (Fig. 2). Again, ermF and tet $M$ showed the largest variation. As there was generally large variation in the degree of changes within and between the farms (Fig. 2) univariate statistics on the changes following different treatments, as shown in Fig. 1 , may not be appropriate, and is therefore not reported.

\section{Test including all variables affecting gene abundance}

To account for the impact of both farm and treatment, a mixed effect model including the random effect of batch was employed for all genes on all combinations of times (T1 to T3, T1 to T2, and T2 to T3). All tests had farm as a significant factor. After employing backwards elimination with an alpha level of 0.05 , the model for tet(W) from T1 to T3 also had treatment strategy as a significant effect, but when applying a Bonferroni correction for multiple comparisons (alpha $=0.05 / 4$, four tests are done on each $\Delta \Delta C_{\mathrm{q}}$ per gene per time pair), this effect disappeared for tet $(\mathrm{W})$. Thus, the multivariant analysis confirmed the preliminary indication from the univariate visualisation (Fig. 1) that treatment strategy did not affect the exit levels of the quantifiable genes (T3 compared to T1).

For prevalence of genes, which was calculated per batch and employing backwards elimination on a model including farm, time, and treatment effects, it was again found that farm was a significant factor, and that a HD treatment increased tet $(\mathrm{A})$ and $\operatorname{tet}(\mathrm{B})$ to higher levels 


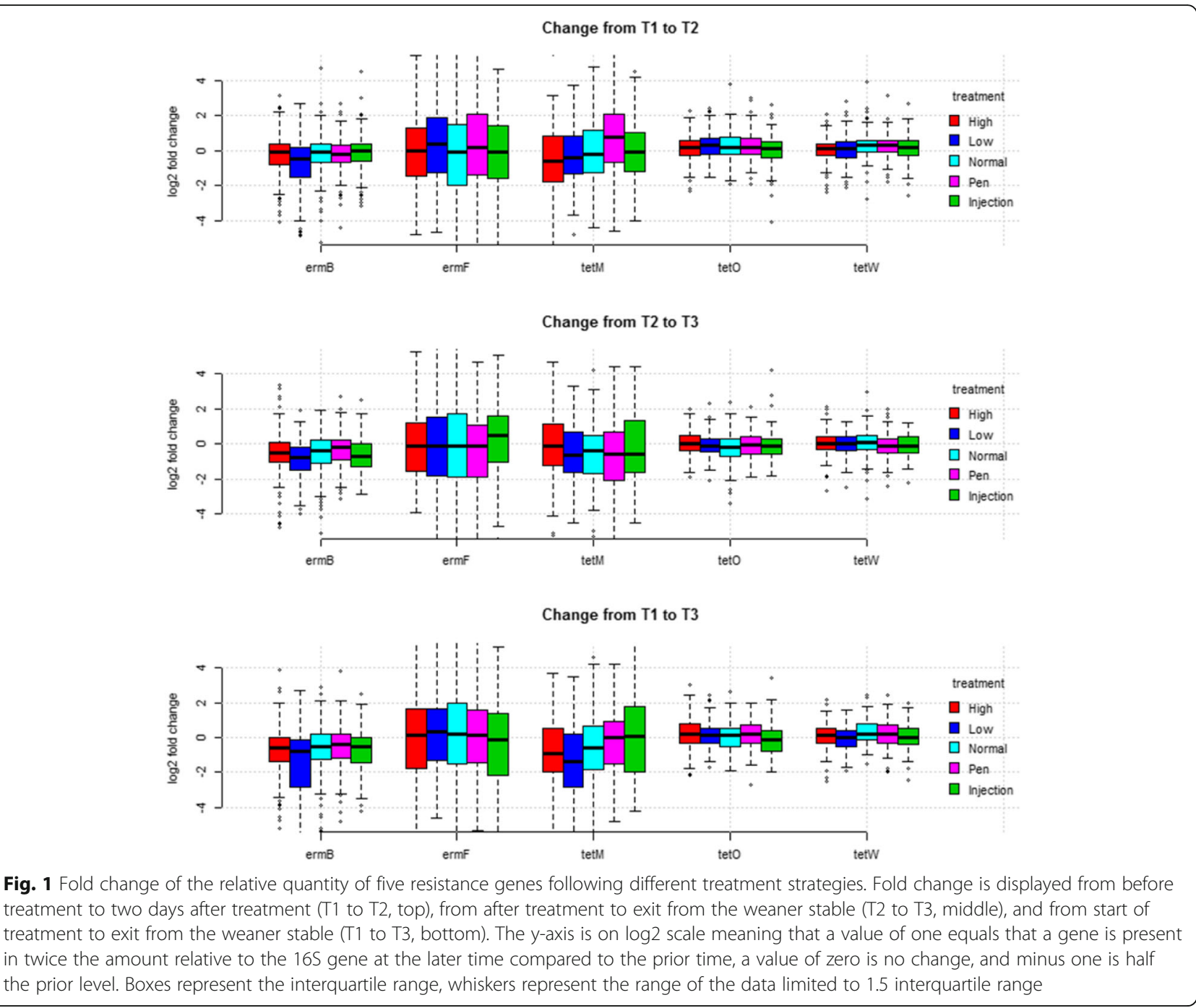

between $\mathrm{T} 1$ and $\mathrm{T} 2$ compared to the other treatment regimens $(p=0.001 / 0.03)$. However, only tet $(\mathrm{A})$ was significant when taking repeated testing into account.

The overall level of some genes also changes over the time in the nursery (from T1 to T3). For ermB a reduction of $48 \%(p=0.004)$ was seen, and for tet $(\mathrm{W})$ an increase of $27 \%(P=0.01)$ was seen. For tet $(\mathrm{A})$, and overall reduction of $19 \%$ points $(p=0.01)$, sulI a reduction of $7 \%$ points $(p=0.03)$, and sulII a reduction of $12 \%$ points $(p<0.0002)$ was observed.

In the PW and IM groups, not all animals were treated. It was therefore possible to test whether treatment with oxytetracycline had any effects on gene levels. For tet $(\mathrm{O})$ and tet $(\mathrm{W})$, the relative change in gene copies was significantly higher from $\mathrm{T} 1$ to $\mathrm{T} 2$ and from $\mathrm{T} 1$ to T3 in treated pigs, also when employing a Bonferroni correction. The treatment increased the levels of tet $(\mathrm{O})$ from $\mathrm{T} 1$ to $\mathrm{T} 2$ with $27 \%(p=0.001)$, tet $(\mathrm{W})$ from $\mathrm{T} 1$ to $\mathrm{T} 2$ with $22 \%(p<0.001)$; $\operatorname{tet}(\mathrm{O})$ from $\mathrm{T} 1$ to $\mathrm{T} 3$ with
$24 \%,(p=0.009)$ and tet $(\mathrm{W})$ from T1 to T3 with $17 \%(p$ $=0.006)$. There were too few whole batches pigs receiving no treatment to test the effect on prevalence of the remaining genes.

\section{Time effects antibiotic resistance gene composition at farm level}

To evaluate the change of AMR gene levels over time longer than the single batch, the levels of $\operatorname{ermB}$, tet $(\mathrm{O})$, and $\operatorname{tet}(\mathrm{W})$ at start of treatments, right after treatment and at the exit from the nursery unit, irrespective of treatment, were plotted over the full time of trial (Additional file 7: Figure S7, Additional file 8: Figure S8, Additional file 9: Figure S9, Additional file 10: Figure S10, Additional file 11: Figure S11). All genes showed drift in the level of abundance on one or more farms over the course of the trial. For comparison, we compared T1 in the first three and the last three batches including at each farm: On Farms 2, 4, and $5 \mathrm{ermB}$ was significantly 


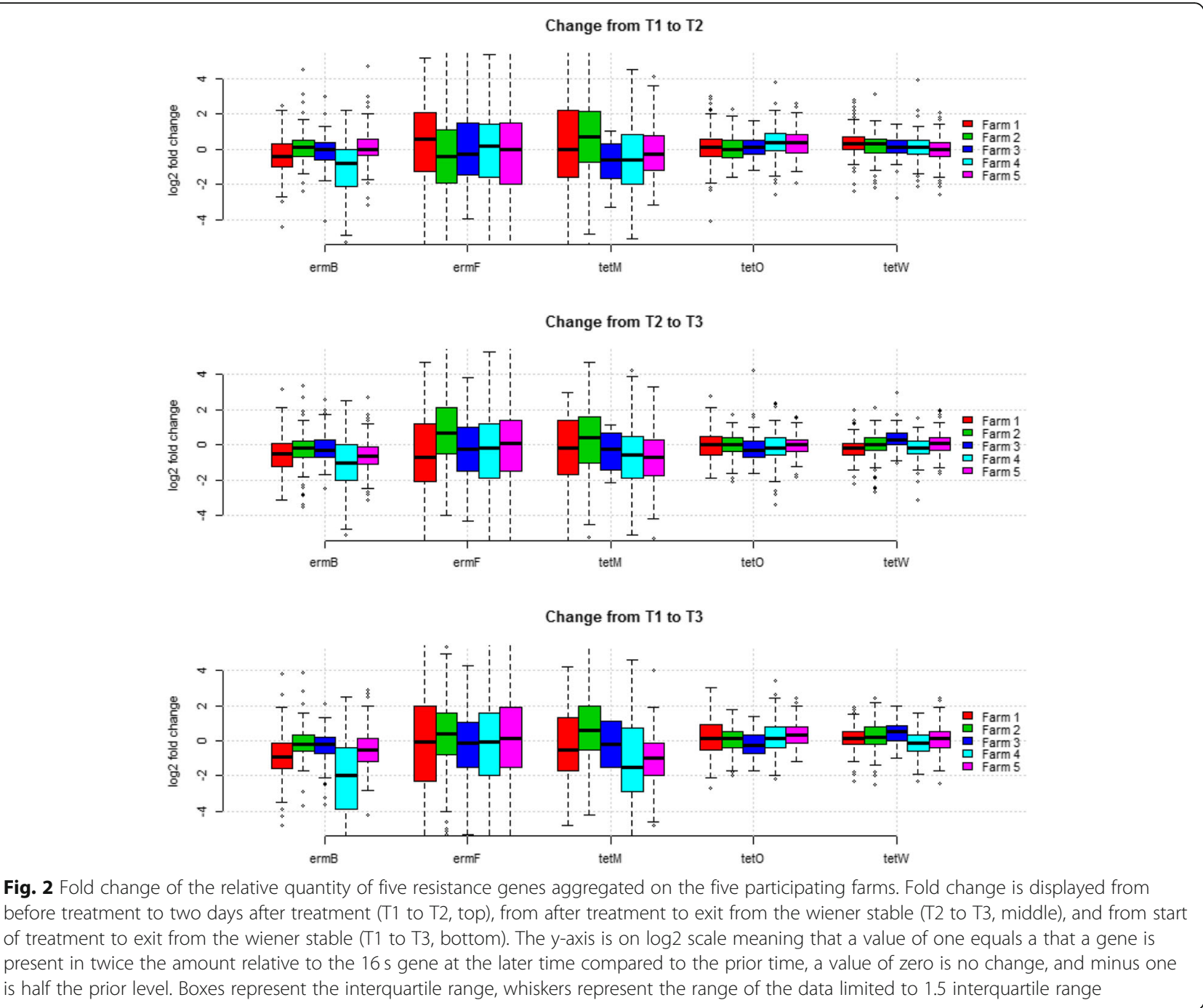

reduced with 37,72 , and 70\% (all $p<0.001$ ). On Farms 1 and 5 tet $(O)$ decreased with 72, and 29\% (both $p<$ $0.001)$, while farm 2 had an increase of $117 \%(p<0.001)$. On Farms 1, 3, and 4 there was significant decrease of tet $(W)$ of 21,16 , and $17 \%(p=0.003, p=0.020, p=$ $0.004)$, while there was an increase at farm 2 of $21 \%$ ( $p=$ 0.05) (Additional file 8: Figure S8, Additional file 9: Figure S9, Additional file 10: Figure S10, Additional file 11: Figure S11, Additional file 12: Figure S12).

Prevalence of AMR genes tet(A), tet(B), sulI, and sulII was also plotted over time (Additional file 13: Figure S13, Additional file 14: Figure S14, Additional file 15: Figure S15, Additional file 16: Figure S16, Additional file 17: Figure S17). These plots also showed changes over time. The behaviour seems more erratic than the quantifiable genes, likely because many of these genes were present in level close to the limit of detection, and so the variation in the results becomes high. Furthermore, when aggregating on batch the number of data points decrease so low $p$-values become rarer, and so there were no significant p-values when correcting for repeated measurements. Though, the closest to significance where the increase of tet(A) over time (at T1) in farms 2 and 5.

\section{Pigs from the same farm have more similar resistance gene composition than pigs from different farms}

A principal component analysis showed that the pigs in farms 2 and 3 had very similar composition of resistance genes (small clusters), while farm 4 had pigs with large variation in gene composition and farms 1 and 5 had medium variation (Fig. 3). When aggregating pigs per batch at T1 (Fig. 4) all farms except farm 4 showed a tendency that chronologically appearing batches clustered close to each other.

\section{Discussion}

The purpose of this study was to investigate how treatment dose and regimen with oxytetracycline affected the 


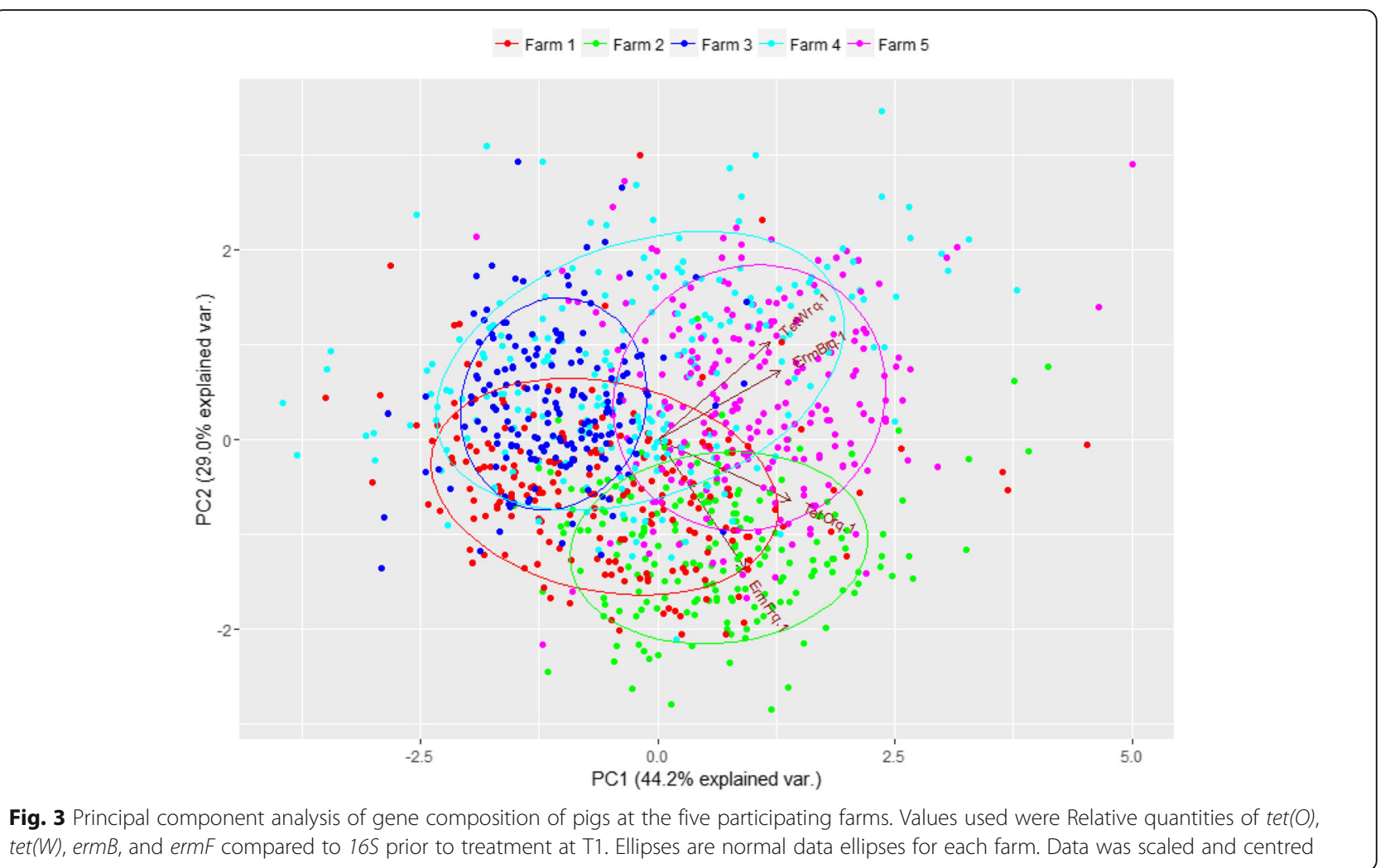

levels of nine AMR genes that are commonly found in the microflora of nursery pigs $(\operatorname{tet}(\mathrm{A}),(\mathrm{B}),(\mathrm{M}),(\mathrm{O}),(\mathrm{W}))$ [39-44], erm (B) and (F) [44-46], sulI and sulII [38, 47, 48]. These included genes that were directly selected by the treatment (the tet genes), and genes that were not expected to be selected by the treatment (the erm and sul genes). Additional inclusion criteria were resistance determinants towards antibiotic classes frequently used of the in Danish pig production, and to be feasible to design $\mathrm{qPCR}$ assays having the same temperature profile. The tetracycline resistance tet genes are broadly disseminated and have been found in a large number Gram

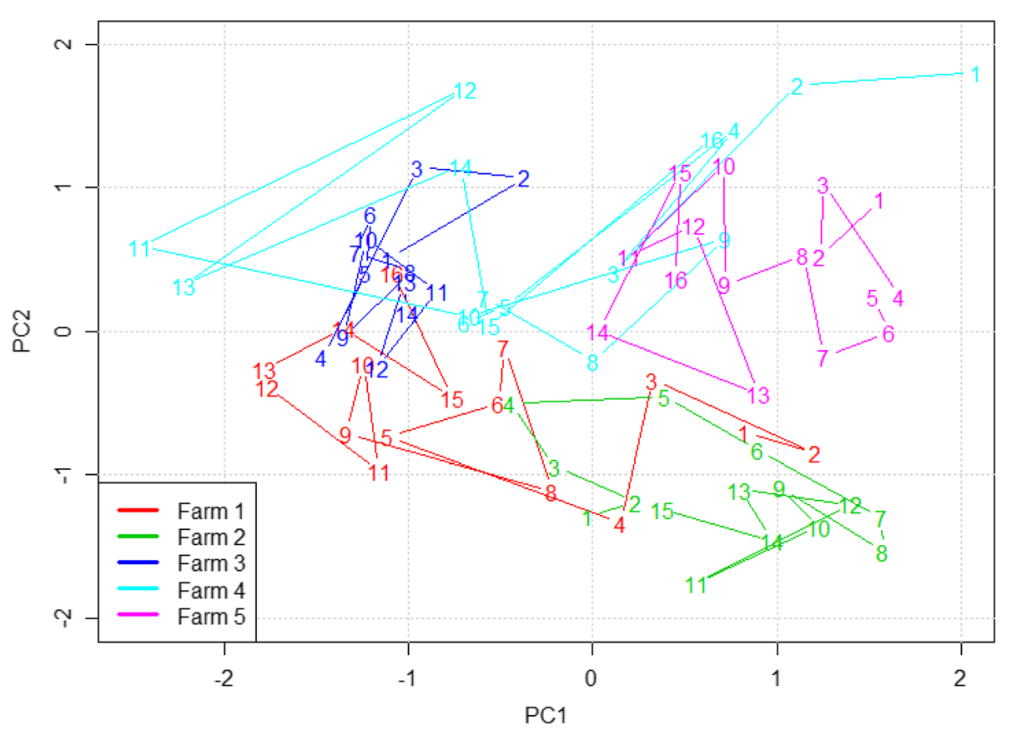

Fig. 4 Principal component analysis of gene composition of pigs at the five participating farms. Numbers are chronologically per farm and indicate the centre of each batch prior to treatment (T1). The PCA transformation is identical to Fig. 3 
negative, Gram positive, aerobic and anaerobic bacteria, where they often are harboured on horizontally transferred genetic elements [49]. The erm genes are associated with transposons also widely distributed in many bacterial genera and species where the tetracycline resistance gene tet $(\mathrm{Q})$ is often linked to $\operatorname{erm}(\mathrm{F})$ and tet $(\mathrm{M})$ to $\operatorname{erm}(\mathrm{B})[50,51]$. The study enabled a unique incorporation of variation between farms and pigs in the evaluation of the effect of different oxytetracycline treatments.

A large number of studies have investigated the effect of antibiotic therapy on antibiotic resistance. The majority of these studies have concerned phenotypic resistance in coliform indicator bacteria [52-55]. Recent developments in DNA based molecular technologies, however, have enabled metagenomic surveillance of resistance determinants in microbial communities [21, 24, 56-58] which allow a much more comprehensive sampling of the AMR gene prevalence [59]. Here we study the effects of different oxytetracycline treatment strategies on the levels of nine resistance genes under field conditions using high capacity qPCR.

There was a significant decrease in the relative levels of three out of four non-tet genes from T1 to T3 (Figs. S12S17). However, the use of oxytetracycline significantly increased the relative levels of the four tetracycline resistance genes; tet $(\mathrm{A}), \operatorname{tet}(\mathrm{B}), \operatorname{tet}(\mathrm{O})$, and $\operatorname{tet}(\mathrm{W})($ Figs. 1 and 2, S12S17) during treatment from $\mathrm{T} 1$ to $\mathrm{T} 2$, followed by a slight decline after treatment from $\mathrm{T} 2$ to $\mathrm{T} 3$, but to an overall increasing effect. $T e t(\mathrm{O})$ and tet $(\mathrm{W})$ encode closely related tetracycline ribosomal protection proteins and are ubiquitously found in gut and soil microbiomes [21, 22, 38, 60, 61]. tet $(\mathrm{A})$, and tet $(\mathrm{B})$, encodes proteins that belong to the major facilitator superfamily (MFS) which export tetracycline from the cell [62]. This effect of treatment correlates well with the results of a phenotypic investigation of tetracycline resistance in coliform bacteria from the same clinical trial published elsewhere [55]. However, the increase of abundance was not generally dose dependent (except for tet(A)) or dependent on whether individual, pen-wise or batch treatment regimens were used, and the overall amount of all the AMR genes included in the study decreased over time in the nursery period, which confirms previous observations [63]. Moreover, the abundance of tet $(\mathrm{M})$, which also encodes a Group-1 ribosomal protection protein of same protein family as tet $(\mathrm{O})$ and $\operatorname{tet}(\mathrm{W})$, did not increase significantly during the trial, but followed the general decreasing trend shown by genes not associated with tetracycline resistance (Fig. 1 and Additional file 15: Figure S15) [64]. The tetracycline resistance genes investigated in the current study are examples of very abundant genes with widespread distribution, and they can be situated both on the chromosome and on horizontally transferred vectors $[64,65]$. Differences in genetic context may be a contributing factor in the differential response to oxytetracycline treatment that was observed for $\operatorname{tet}(\mathrm{O})$ and $\operatorname{tet}(\mathrm{W})$ compared to tet $(\mathrm{M})$. A gene encoded on a plasmid or other mobile genetic elements would be expected to have a more dynamic response towards selection due to gene amplification and changes in copy number. It has been recently shown that Yersinia pseudotuberculosis regulate plasmid copy number in response to environmental cues to increase expression of plasmid borne virulence factors and a similar regulatory mechanisms could be involved in the dynamic regulation of AMR gene copy numbers of resistance genes carried on plasmids [66]. However, this mechanism remains to be shown to be important in an AMR context. Moreover, a resistance gene situated on a transferable element can quickly transfer to a new host while a chromosomally encoded gene mainly increases in numbers by following the host proportion in the community. This possibility highlights a complication of using relative values of gene abundance in whole community samples to study gene abundance, because a gene can paradoxically increase in prevalence within the host's bacterial population, but decrease in relative abundance due to large changes in the microbiome composition. This could have implications for surveillance using DNA based methods, because zoonotic pathogens, which frequently have small populations, could have a proportionally high resistance level but a low over all relative prevalence level. Oxytetracycline dose and use of batch treatment as opposed to pen wise and single animal injection treatment have previously been shown to improve the clinical efficacy of treatment of Lawsonia intracellularis infection $[33,36]$. Therefore, batch treatment may in some situations be considered a safe and effective treatment regimen for intestinal infection in pigs. In order to reduce AMR a strategy for reducing the number of treatments rather than the treatment regimens (batch, penwise, injection) should be preferred [64].

There was a large variation in the amount of AMR genes between the farms included in the clinical trial both in relative gene levels and change over time, (Fig. 2 and Additional file 7: Figure S7, Additional file 8: Figure S8, Additional file 9: Figure S9, Additional file 10: Figure S10, and Additional file 11: Figure S11) and pigs from the same farm had a more similar resistance gene composition than pigs from different farms (Fig. 3). AMR gene levels also fluctuated significantly over time in the individual farms indicating that batch resistance-gene composition play an important role in the overall AMR gene abundance (Fig. 4). AMR is influenced by factors such as animal husbandry, geographic location, and trade connections. Interestingly it was recently shown that the resistance composition of the sow's bacterial flora strongly influenced the resistance gene prevalence in the offspring even though the piglets were moved to other farms [37]. This observation could explain the 
similarity between pigs on the same farm due to the increased probability that they have a similar origin and disease/treatment history. Furthermore, the different composition of genes on different farms (Figs. 3-4) may be an explanatory factor of the different response seen to treatment (Fig. 2).

When all factors were included in a mixed effect model, only tet(A) showed effect of treatment dose, and only $\operatorname{tet}(\mathrm{O})$ and $\operatorname{tet}(\mathrm{W})$ were significantly affected by oxytetracycline. That treatment but not treatment mode was significant is likely because the numbers of untreated pigs in the treatment groups IM and PW were low, and non-treated animals in the IM group resided inside the same pens as treated animals.

\section{Conclusion}

This study exemplifies the complexity of AMR gene abundance in real life situations. Oxytetracycline resistance gene levels were slightly but significantly increased during treatment, but only for four out of nine resistance genes included in the study. The analysis also shows that non-treatment factors such as animal history and management procedures may strongly influence the resistance levels on the individual farm and that the effect of a single antibiotic treatment on resistance levels at the weaning stage may have a minor influence on the overall resistance gene abundance and prevalence. The study also shows the utility of using DNA based analysis methods that can cheaply and quickly analyse a large number of samples: however, the study also illustrates the large variability in gene levels under natural conditions, which complicates analysis of the population genetics and microbial ecology of resistance gene.

\section{Methods}

\section{Clinical field trial}

The randomized clinical field trial has previously been described in two studies measuring the effect of varying treatment-doses and treatment-routes on the effect of oxytetracycline (OTC) treatment against $L$. intracellularis induced diarrhoea [33, 36]. Briefly, five farms were selected based on sampling to represent a typical problem with $L$. intracellularis (LI) induced diarrhoea amongst the clients of two specialised veterinary pig practices [33, 36, 55]. Farms vaccinated against LI or high risk of acute medication were excluded. In each farm, 15 batches were included in the study after being weaned and followed until the end of the nursery period seven weeks after they were introduced into the nursery unit. A batch was defined as a group of nursery pigs all weaned at the same time, housed into the same large room, and sub-divided into smaller compartments, the pens. The number of pigs per batch ranged from 240 to 600 and the number of pens per batch ranged from 8 to
20 depending on which 'room' was used at the specific farm. In each batch, 15 animals, randomly distributed over pens, were selected as trial pigs [33,36]. and all trial pigs were ear tagged with a unique ID as previously described in $[33,36]$.

Each batch was monitored once a week for outbreak of diarrhoea. The estimation of diarrhoea was done by trained veterinarians, responsible for initiating treatment. When an outbreak was diagnosed, one of five treatment protocols, each consisting of a treatment once a day for five days was used: Oral batch-treatment in water with a standard dose of $10 \mathrm{mg} / \mathrm{kg}$ OTC (Terramycin $^{\circ}$ Vet. 20\%, Orion Pharma) (ND), oral batch- treatment in water with a high dose of $20 \mathrm{mg} / \mathrm{kg}$ OTC (HD); oral batch-treatment in water with a low dose of $5 \mathrm{mg} /$ kg OTC (LD), oral pen-wise treatment in water with a standard dose of $10 \mathrm{mg} / \mathrm{kg}$ OTC (PW) or individual intra muscular treatment with a standard dose of $10 \mathrm{mg} / \mathrm{kg}$ OTC (IM). For batch treatment, an outbreak was defined as more than 0.5 deposits of stool on average per pen floor or more than $25 \%$ of the pigs with clinical diarrhoea. Pen-wise treatment was initiated when the outbreak criteria was fulfilled for a pen (a smaller subset of the batch housed in the same room), while individual treatment was initiated when animals showed typical signs of diarrhoea (loose to watery faeces or poor body score). For batch and pen-wise treatment, it was ensured that the medicine was consumed within $24 \mathrm{~h}$. Each protocol was repeated 3 times on each farm, and the order of treatment protocols was chosen at random to avoid bias.

\section{Sampling}

Faecal samples were collected as previously described by Græsbøll et al. (2017) [55]: Briefly, samples were collected from all trial pigs between October 2011 and April 2013, either at defecation or per rectum. Samples were collected from all pigs at three time points: Time point 1 (T1) was the first day of treatment; immediately before antibiotic administration, Time point 2 (T2) was two days after the end of treatment, and Time point 3 (T3) was when pigs were moved from the nursery unit to finisher stables. The clinical study was designed to be able to measure differences in production parameters during the time in the nursery unit, most importantly growth rate. Samples were stored in $40 \mathrm{ml}$ containers and shipped to the laboratory in cooled boxes.

\section{DNA extraction}

Total DNA was extracted from the samples, using the Maxwell 16 LEV Blood DNA Kit (Promega Corporation, Madison, WI, USA) as described by Clasen et al. [25]. In short, samples were homogenized in a cell and tissue disruptor (Tissuelyser II, Qiagen, Hilden, Germany) with $5 \mathrm{~mm}$ 
stainless steel beads (Qiagen, Hilden, Germany) and beadbeated for $2 \mathrm{~min}$ in a $25 \mathrm{mg} / \mathrm{ml}$ lysozyme (Sigma-Aldrich, Denmark A/S)) buffer. Samples were then transferred to Maxwell $^{\circ}$ extraction kit cartridges and DNA was extracted in according to manufacturer's instructions. DNA concentrations were measured and purity were assessed by the 260/280 nm-ratio using the NanoDropND-1000 spectrophotometer (NanoDrop Technologies Inc., Wilmington, DE, USA). Samples were diluted to $40 \mathrm{ng} / \mu \mathrm{l}$ in nuclease free water (Qiagen, Hilden, Germany) and stored at $-20^{\circ} \mathrm{C}$ until further processing.

\section{Real-time qPCR primers}

qPCR amplifications for the quantification of $\operatorname{tet}(A)$, tet $(B)$, tet $(M)$, tet $(O)$, and tet $(W)$, representing genes that were directly selectable by the tetracycline treatment, and ermB, ermF, sulI and sulII representing genes encoding resistances that were unrelated to the tetracycline treatment, and 16S rRNA-gene as an approximation for the number of bacteria in total DNA extracted from pig faecal samples were performed using the Fluidigm HD Biomark system (Fluidigm Corporation, South San Francisco, CA, USA). Levels of the AMR genes, were quantified using the high-capacity qPCR chip Gene Expression $192 \times 24$ (Fluidigm Corporation, South San Francisco, CA, USA) with two technical replicates using $16 \mathrm{~S}$ as reference gene as previously described [25]. Primers used are listed in Additional file 18: Table S1).

\section{Statistics}

Quantifiable genes was put on the form of relative abundance $\left(\Delta C_{\mathrm{q}}=\left(\mathrm{C}_{\mathrm{q}, 16 \mathrm{~s}}\right)_{\mathrm{Tx}}-\left(\mathrm{C}_{\mathrm{q}} \text {, gene }\right)_{\mathrm{Tx}}\right)$ or relative fold change $\left(\Delta \Delta \mathrm{C}_{\mathrm{q}}=\left(\mathrm{C}_{\mathrm{q}, 16 \mathrm{~s}}{ }^{-} \mathrm{C}_{\mathrm{q}} \text {, gene }\right)_{\mathrm{Ty}}-\left(\mathrm{C}_{\mathrm{q}, 16 \mathrm{~s}}{ }^{-} \mathrm{C}_{\mathrm{q}} \text {, gene }\right)_{\mathrm{Tx}}\right)$, were $\mathrm{Tx}$ and $\mathrm{Ty}$ represent different time points. Test for significant change in relative quantities $\left(R Q=\Delta \Delta C_{\mathrm{q}}\right)$ between time points in treatment strategies or on farms were performed using a two-sided t-test with the null hypotheses being no change. To determine the effect of treatment regime including all factors $\Delta \Delta \mathrm{C}_{\mathrm{q}}$ values were also tested using farm and treatment strategy as fixed effects and batch as random effect. Furthermore, to determine the effect of treatment of the individual pig, $\Delta \Delta \mathrm{C}_{\mathrm{q}}$ values were tested using farm and treatment as fixed effects and batch as random effect. Changes reported in percentages are equivalent to $\left(2^{\Delta \Delta C q}-1\right)^{*} 100 \%$. In case of genes where low abundance resulted in difficulty of quantifying, the genes were aggregated to prevalence per batch and tested using linear regression using farm, time, farm:time, and treatment:time as fixed effects.

Tests using fixed and random effects were performed using lmer from the package lme4, and backwards elimination was performed using step from the package lmerTest. Linear regression was performed using the function glm with a Gaussian family. Principal component analysis was performed on the relative quantities using prcomp with scaling and centering options enabled. All tests were performed in $\mathrm{R}$ version > 3.2 (R Core Team, 2015).

\section{Supplementary information}

Supplementary information accompanies this paper at https://doi.org/10. 1186/s12866-019-1619-z.

\begin{abstract}
Additional file 1: Figure S1. Relative quantities $(R Q)$ of tet( $O)$, tet $(W)$, and ermB to 165 of all batches chronologically onfarm 1. Top graph is values prior to treatment (T1), middle graph values two days after treatment (T2), and bottom graph is values at exit from nursery unit (T3). Dots are median values of each batch. Lines are smoothed values of the data points. Coloured areas are smoothed areas of the interquartile range.
\end{abstract}

Additional file 2: Figure S2. Relative quantities (RQ) of tet(O), tet( $W$, and ermB to 165 of all batches chronologically farm 2. Top graph is values prior to treatment ( $(\mathrm{T})$, middle graph values two days after treatment (T2), and bottom graph is values at exit from nursery unit (T3). Dots are median values of each batch. Lines are smoothed values of the data points. Coloured areas are smoothed areas of the interquartile range.

Additional file 3: Figure S3. Relative quantities (RQ) of tet( $O)$, tet( $W$ ), and ermB to 165 of all batches chronologically on farm 3. Top graph is values prior to treatment (T1), middle graph values two days after treatment (T2), and bottom graph is values at exit from nursery unit (T3). Dots are median values of each batch. Lines are smoothed values of the data points. Coloured areas are smoothed areas of the interquartile range.

Additional file 4: Figure S4. Relative quantities $(R Q)$ of tet( $O)$, tet $(W)$, and ermB to 165 of all batches chronologically on farm 4. Top graph is values prior to treatment (T1), middle graph values two days after treatment (T2), and bottom graph is values at exit from nursery unit (T3). Dots are median values of each batch. Lines are smoothed values of the data points. Coloured areas are smoothed areas of the interquartile range.

Additional file 5: Figure S5. Relative quantities (RQ) of tet( $O)$, tet( $W$ ), and ermB to 165 of all batches chronologically on farm 5. Top graph is values prior to treatment (T1), middle graph values two days after treatment (T2), and bottom graph is values at exit from nursery unit (T3). Dots are median values of each batch. Lines are smoothed values of the data points. Coloured areas are smoothed areas of the interquartile range.

Additional file 6: Figure S6. Prevalence of sull, sull, tet(A), and tet(B). Stratified by sampling time and treatment.

Additional file 7: Figure S7. Prevalence of sull, sull, tet(A), and tet(B). Stratified by sampling time and farm.

Additional file 8: Figure S8. Relative quantities of ermB at times $\mathrm{T} 1, \mathrm{~T} 2$ and T3. Stratified by treatment and farm.

Additional file 9: Figure S9. Relative quantities of ermF at times T1, T2 and T3. Stratified by treatment and farm.

Additional file 10: Figure S10. Relative quantities of tetM at times T1, T2 and T3. Stratified by treatment and farm.

Additional file 11: Figure S11. Relative quantities of tet $(\mathrm{O})$ at times $\mathrm{T1}$, T2 and T3. Stratified by treatment and farm.

Additional file 12: Figure S12. Relative quantities of tet $(\mathrm{W})$ at times $T 1$, T2 and T3. Stratified by treatment and farm.

Additional file 13: Figure S13. Prevalence of tet(A), tet(B), sull and sulll of all batches chronologically on farm 1. Top graph is values prior to treatment (T1), middle graph values two days after treatment (T2), and bottom graph is values at exit from nursery unit (T3). Dots are median values of each batch. Lines are smoothed values of the data points.

Additional file 14: Figure S14. Prevalence of tet(A), tet(B), sull and sulll of all batches chronologically on farm 2. Top graph is values prior to 
treatment (T1), middle graph values two days after treatment (T2), and bottom graph is values at exit from nursery unit (T3). Dots are median values of each batch. Lines are smoothed values of the data points.

Additional file 15: Figure S15. Prevalence of tet( $A)$, tet( $B)$, sull and sulll of all batches chronologically on farm 3 . Top graph is values prior to treatment (T1), middle graph values two days after treatment (T2), and bottom graph is values at exit from nursery unit (T3). Dots are median values of each batch. Lines are smoothed values of the data points.

Additional file 16: Figure S16. Prevalence of tet( $(A)$, tet(B), sull and sulll of all batches chronologically on farm 4. Top graph is values prior to treatment (T1), middle graph values two days after treatment $\mathrm{T} 2$ ), and bottom graph is values at exit from nursery unit (T3). Dots are median values of each batch. Lines are smoothed values of the data points,

Additional file 17: Figure S17. Prevalence of tet( $A)$, tet( $B)$, sull and sulll of all batches chronologically on farm 5 . Top graph is values prior to treatment (T1), middle graph values two days after treatment (T2), and bottom graph is values at exit from nursery unit (T3). Dots are median values of each batch. Lines are smoothed values of the data points.

\section{Additional file 18: Table S1.}

\section{Abbreviations}

AMR: Antimicrobial resistance; HD: High dose; IM: Injection treatment group; LD: Low dose; ND: Normal dose; OTC: Oxytetracyclin; PW: Pen wise treatment group

\section{Acknowledgements}

Not applicable.

\section{Authors' contributions}

KG: Performed experiments, analyzed data and wrote the paper. IL: Designed research, performed experiments, analyzed data and drafting of article and/ or critical revision. JC: Performed experiments and analyzed data and drafting of article and/or critical revision. CB: Analyzed data and drafting of article and/or critical revision. JN: Designed research analyzed data and drafting of article and/or critical revision. LC: Designed research analyzed data and drafting of article and/or critical revision. ØA: Designed research analyzed data and drafting of article and/or critical revision. JO: Designed research analyzed data and drafting of article and/or critical revision. AF: Designed research, performed experiments, analyzed data and wrote the paper. All authors read and approved the final version of the manuscript.

\section{Funding}

The study was supported by a grant from the Danish Innovation Fund (Grant number 0603-00385B). The funder had no influence on the design or the execution of the study, nor on any parts on this manuscript.

\section{Availability of data and materials}

All data generated or analyzed during this study are included in this published article [and its supplementary information files].

\section{Ethics approval and consent to participate}

The study was performed as a randomised clinical trial. Data were collected from October 2011 to April 2013. The study was approved by the Danish Medicines Agency (License no. 2011090862/2012053751). Participating herd owners signed a written "Owner informed consent", which explained the scope of the field trial.

\section{Consent for publication}

Not applicable.

\section{Competing interests}

The authors declare that they have no competing interests.

\section{Author details}

'DTU Compute, Technical University of Denmark, Kongens Lyngby, Denmark. ${ }^{2}$ Department of Veterinary and Animal Sciences, University of Copenhagen, Copenhagen, Denmark. ${ }^{3}$ DTU Vet. Technical University of Denmark, Kongens Lyngby, Denmark. ${ }^{4}$ Present address: SSI, Copenhagen, Denmark. ${ }^{5}$ DTU BioEngineering, Technical University of Denmark, Kongens Lyngby, Denmark.
Received: 8 March 2019 Accepted: 22 October 2019

Published online: 02 December 2019

\section{References}

1. Wright GD. Solving the antibiotic crisis. ACS Infectious Diseases. 2015;1(2): 80-4.

2. World Health Organization: Antimicrobial resistance: global report on surveillance. In. Geneva, Switzerland: World Health Organization, Geneva, Switzerland; 2014

3. O'Neill J: Tackling Drug-Resistant Infections Globally: final report and recommendations. Review on Antimicrobial Resistance. In.: HM Government London, United Kingdom; 2016.

4. House W. National action plan for combating antibiotic-resistant bacteria. The White House, Washington, DC, United States of America: In; 2015.

5. Shallcross LJ, Davies SC. The world health assembly resolution on antimicrobial resistance. J Antimicrob Chemother. 2014

6. D'Costa VM, King CE, Kalan L, Morar M, Sung WWL, Schwarz C, Froese D, Zazula G, Calmels F, Debruyne $\mathrm{R}$, et al. Antibiotic resistance is ancient. Nature. 2011;477(7365):457-61.

7. Wright $\mathrm{GD}$, Poinar $\mathrm{H}$. Antibiotic resistance is ancient: implications for drug discovery. Trends Microbiol. 2012;20(4):157-9.

8. D'Costa VM, McGrann KM, Hughes DW, Wright GD. Sampling the antibiotic resistome. Science. 2006;311(5759):374-7.

9. Allen HK, Donato J, Wang HH, Cloud-Hansen KA, Davies J, Handelsman J. Call of the wild: antibiotic resistance genes in natural environments. Nat Rev Microbiol. 2010:8(4):251-9.

10. Aminov RI. The role of antibiotics and antibiotic resistance in nature. Environ Microbiol. 2009:11(12):2970-88.

11. Levy SB, FitzGerald GB, Macone AB. Changes in intestinal Flora of farm personnel after introduction of a tetracycline-supplemented feed on a farm. N Engl J Med. 1976;295(11):583-8.

12. Moon DC, Tamang MD, Nam HM, Jeong JH, Jang GC, Jung SC, Park YH, Lim SK. Identification of livestock-associated methicillin-resistant Staphylococcus aureus isolates in Korea and molecular comparison between isolates from animal carcasses and slaughterhouse workers. Foodborne Pathog Dis. 2015; 12(4):327-34.

13. Smith DL, Harris AD. Johnson Ja, Silbergeld EK, Morris JG: animal antibiotic use has an early but important impact on the emergence of antibiotic resistance in human commensal bacteria. Proc Natl Acad Sci U S A. 2002;99: 6434-9.

14. Silbergeld EK, Graham J, Price LB. Industrial food animal production, antimicrobial resistance, and human health. Annu Rev Public Health. 2008, 29:151-69.

15. Rao S, Van Donkersgoed J, Bohaychuk V, Besser T, Song X-M, Wagner B, Hancock D, Renter D, Dargatz D, Morley PS. Antimicrobial drug use and antimicrobial resistance in enteric Bacteria among cattle from Alberta feedlots. Foodborne Pathog Dis. 2009;7(4):449-57.

16. Morley PS, Dargatz DA, Hyatt DR, Dewell GA, Patterson JG, Burgess BA, Wittum TE. Effects of restricted antimicrobial exposure on antimicrobial resistance in fecal Escherichia coli from feedlot cattle. Foodborne Pathog Dis. 2010;8(1):87-98.

17. Hurd HS, Doores S, Hayes D, Mathew A, Maurer J, Silley P, Singer RS, Jones RN. Public health consequences of macrolide use in food animals: a deterministic risk assessment. J Food Prot. 2004:67(5):980-92.

18. Hurd HS, Malladi S. A stochastic assessment of the public health risks of the use of macrolide antibiotics in food animals. Risk Anal. 2008;28(3):695-710.

19. Alban L, Nielsen EO, Dahl J. A human health risk assessment for macrolideresistant campylobacter associated with the use of macrolides in Danish pig production. Prev Vet Med. 2008;83(2):115-29.

20. Alali WQ, Scott HM, Harvey RB, Norby B, Lawhorn DB, Pillai SD. Longitudinal study of antimicrobial resistance among Escherichia coli isolates from integrated multisite cohorts of humans and swine. Appl Environ Microbiol. 2008;74(12):3672-81.

21. Noyes NR, Yang X, Linke LM, Magnuson RJ, Dettenwanger A, Cook S, Geornaras I, Woerner DE, Gow SP, McAllister TA, et al. Resistome diversity in cattle and the environment decreases during beef production. Elife. 2016;5: e13195.

22. Zhu YG, Johnson TA, Su JQ, Qiao M, Guo GX, Stedtfeld RD, Hashsham SA, Tiedje JM. Diverse and abundant antibiotic resistance genes in Chinese swine farms. Proc Natl Acad Sci U S A. 2013;110(9):3435-40. 
23. Johnson TA, Stedtfeld RD, Wang Q, Cole JR, Hashsham SA, Looft T, Zhu YG, Tiedje JM. Clusters of antibiotic resistance genes enriched together stay together in swine agriculture. MBio. 2016;7(2):e02214-5.

24. Munk P, Andersen VD, de Knegt $L$, Jensen MS, Knudsen BE, Lukjancenko O, Mordhorst H, Clasen J, Agerso Y, Folkesson A, et al. A sampling and metagenomic sequencing-based methodology for monitoring antimicrobial resistance in swine herds. J Antimicrob Chemother. 2017;72(2):385-92.

25. Clasen J, Mellerup A, Olsen JE, Angen Ø, Folkesson A, Halasa T, Toft N, Birkegård AC. Determining the optimal number of individual samples to pool for quantification of average herd levels of antimicrobial resistance genes in Danish pig herds using high-throughput qPCR. Vet Microbiol. 2016;189:46-51.

26. EMA: European medicines agency, European surveillance of veterianryantimicrobial consumption, 2014, Sales of veterinary antimicrobial agents in26 EU/EEA countries in 2012, (EMA/333921/2014). In.; 2014: (EMA/333921/332014).

27. Pluske JR, Pethick DW, Hopwood DE, Hampson DJ. Nutritional influences on some major enteric bacterial diseases of pig. Nutr Res Rev. 2002;15(2):333-71.

28. Pedersen KS, Johansen $M$, Angen $\varnothing$, Jorsal SE, Nielsen JP, Jensen TK, Guedes R, Ståhl M, Bækbo P. Herd diagnosis of low pathogen diarrhoea in growing pigs - a pilot study. Ir Vet J. 2014;67(1):24.

29. Hybschmann GK, Ersboll AK, Vigre H, Baadsgaard NP, Houe H. Herd-level risk factors for antimicrobial demanding gastrointestinal diseases in Danish herds with finisher pigs: a register-based study. Prev Vet Med. 2011;98(2-3):190-7.

30. Moreno MA. Survey of quantitative antimicrobial consumption per production stage in farrow-to-finish pig farms in Spain. Vet Rec Open. 2014; 1(1):e000002.

31. Burow E, Simoneit C, Tenhagen BA, Kasbohrer A. Oral antimicrobials increase antimicrobial resistance in porcine E. coli--a systematic review. Prev Vet Med. 2014;113(4):364-75

32. Ungemach FR, Muller-Bahrdt D, Abraham G. Guidelines for prudent use of antimicrobials and their implications on antibiotic usage in veterinary medicine. Int J Med Microbiol. 2006;296(Suppl 41):33-8.

33. Larsen I, Nielsen SS, Olsen JE, Nielsen JP. The efficacy of oxytetracycline treatment at batch, pen and individual level on Lawsonia intracellularis infection in nursery pigs in a randomised clinical trial. Prev Vet Med. 2016;124:25-33.

34. Agers $\varnothing$ Y, Bager F, Boel J, Helwigh B, Borck Høg B, Jensen LB, de Knegt $L$, Korsgaard H, Larsen LS, Sørensen AIV et al: DANMAP 2013. 2014.

35. OIE: Terrestrial animal health code. 2016.

36. Larsen I, Hjulsager CK, Holm A, Olsen JE, Nielsen SS, Nielsen JP. A randomised clinical trial on the efficacy of oxytetracycline dose through water medication of nursery pigs on diarrhoea, faecal shedding of Lawsonia intracellularis and average daily weight gain. Prev Vet Med. 2016;123:52-9.

37. Birkegard AC, Ersboll AK, Halasa T, Clasen J, Folkesson A, Vigre H, Toft N. Spatial patterns of antimicrobial resistance genes in a cross-sectional sample of pig farms with indoor non-organic production of finishers. Epidemiol Infect. 2017;145(7):1418-30.

38. Schmidt GV, Mellerup A, Christiansen LE, Stahl M, Olsen JE, Angen O. Sampling and pooling methods for capturing herd level antibiotic resistance in swine feces using qPCR and CFU approaches. PLoS One. 2015;10(6):e0131672.

39. Yu Z, Michel FC Jr, Hansen G, Wittum T, Morrison M. Development and application of real-time PCR assays for quantification of genes encoding tetracycline resistance. Appl Environ Microbiol. 2005;71(11):6926-33.

40. Holzel CS, Harms KS, Kuchenhoff H, Kunz A, Muller C, Meyer K, Schwaiger K, Bauer J. Phenotypic and genotypic bacterial antimicrobial resistance in liquid pig manure is variously associated with contents of tetracyclines and sulfonamides. J Appl Microbiol. 2010;108(5):1642-56.

41. Kazimierczak KA, Scott KP, Kelly D, Aminov RI. Tetracycline resistome of the organic pig gut. Appl Environ Microbiol. 2009;75(6):1717-22.

42. Chee-Sanford JC, Mackie RI, Koike S, Krapac IG, Lin YF, Yannarell AC, Maxwell $S, A m i n o v$ RI. Fate and transport of antibiotic residues and antibiotic resistance genes following land application of manure waste. J Environ Qual. 2009;38(3):1086-108.

43. De Leener E, Martel A, Decostere A, Haesebrouck F. Distribution of the erm (B) gene, tetracycline resistance genes, and Tn1545-like transposons in macrolide- and lincosamide-resistant enterococci from pigs and humans. Microb Drug Resist. 2004;10(4):341-5.

44. Garofalo C, Vignaroli C, Zandri G, Aquilanti L, Bordoni D, Osimani A, Clementi F, Biavasco F. Direct detection of antibiotic resistance genes in specimens of chicken and pork meat. Int J Food Microbiol. 2007;113(1):75-83.

45. Chen J, Yu Z, Michel FC Jr. Wittum T, Morrison M. Development and application of real-time PCR assays for quantification of erm genes conferring resistance to macrolides-lincosamides-streptogramin B in livestock manure and manure management systems. Appl Environ Microbiol. 2007;73(14):4407-16.

46. Knapp CW, Zhang W, Sturm BSM, Graham DW. Differential fate of erythromycin and beta-lactam resistance genes from swine lagoon waste under different aquatic conditions. Environ Pollut. 2010;158(5):1506-12.

47. Hammerum AM, Sandvang D, Andersen SR, Seyfarth AM, Porsbo $L$, Frimodt-Moller N, Heuer OE. Detection of sul1, sul2 and sul3 in sulphonamide resistant Escherichia coli isolates obtained from healthy humans, pork and pigs in Denmark. Int J Food Microbiol. 2006;106(2):235-7.

48. Byrne-Bailey KG, Gaze WH, Kay P, Boxall AB, Hawkey PM, Wellington EM. Prevalence of sulfonamide resistance genes in bacterial isolates from manured agricultural soils and pig slurry in the United Kingdom. Antimicrob Agents Chemother. 2009;53(2):696-702.

49. Roberts M, Schwarz S, Aarts H. Erratum: Acquired antibiotic resistance genes: an overview. Front Microbiol. 2012;3(384):384.

50. Roberts MC, Sutcliffe J, Courvalin P, Jensen LB, Rood J, Seppala H. Nomenclature for macrolide and macrolide-lincosamide-streptogramin B resistance determinants. Antimicrob Agents Chemother. 1999;43(12):2823-30.

51. Clewell DB, Flannagan SE, Jaworski DD. Unconstrained bacterial promiscuity: the Tn916-Tn1545 family of conjugative transposons. Trends Microbiol. 1995;3(6):229-36.

52. Bronzwaer S, Aarestrup F, Battisti A, Bengtsson B, Duran SP, Emborg HD, Kahlmeter G, Mevius D, Regula G, Sanders P, et al. Harmonised monitoring of antimicrobial resistance in Salmonella and campylobacter isolates from food animals in the European Union. Clin Microbiol Infect. 2008;14(6):522-33.

53. Delsol AA, Anjum M, Woodward MJ, Sunderland J, Roe JM. The effect of chlortetracycline treatment and its subsequent withdrawal on multiresistant Salmonella enterica serovar Typhimurium DT104 and commensal Escherichia coli in the pig. J Appl Microbiol. 2003;95(6):1226-34.

54. Wagner BA, Straw BE, Fedorka-Cray PJ, Dargatz DA. Effect of antimicrobial dosage regimen on Salmonella and Escherichia coli isolates from feeder swine. Appl Environ Microbiol. 2008;74(6):1731-9.

55. Graesboll K, Damborg P, Mellerup A, Herrero-Fresno A, Larsen I, Holm A, Nielsen JP, Christiansen LE, Angen O, Ahmed S, et al. Effect of Tetracycline Dose and Treatment Mode on Selection of Resistant Coliform Bacteria in Nursery Pigs. Appl Environ Microbiol. 2017:83(12):00538-00517.

56. Wichmann F, Udikovic-Kolic N, Andrew S, Handelsman J. Diverse Antibiotic Resistance Genes in Dairy Cow Manure. MBio. 2014;5(2):e01017.

57. Li B, Yang Y, Ma L, Ju F, Guo F, Tiedje JM, Zhang T. Metagenomic and network analysis reveal wide distribution and co-occurrence of environmental antibiotic resistance genes. Isme J. 2015;9(11):2490-502.

58. Forslund K, Sunagawa S, Kultima JR, Mende DR, Arumugam M, Typas A, Bork P. Country-specific antibiotic use practices impact the human gut resistome. Genome Res. 2013;23:1163-9.

59. Wright GD. The antibiotic resistome: the nexus of chemical and genetic diversity. Nat Rev Microbiol. 2007;5:175-86.

60. Aminov Rl, Garrigues-Jeanjean N, Mackie Rl. Molecular ecology of tetracycline resistance: development and validation of primers for detection of tetracycline resistance genes encoding ribosomal protection proteins. Appl Environ Microbiol. 2001;67(1):22-32.

61. Scott KP, Melville CM, Barbosa TM, Flint HJ. Occurrence of the new tetracycline resistance gene tet(W) in bacteria from the human gut. Antimicrob Agents Chemother. 2000:44(3):775-7.

62. Paulsen IT, Brown MH, Skurray RA. Proton-dependent multidrug efflux systems. Microbiol Rev. 1996;60(4):575-608.

63. Langlois BE, Dawson KA, Leak I, Aaron DK. Effect of age and housing location on antibiotic resistance of fecal coliforms from pigs in a nonantibiotic-exposed herd. Appl Environ Microbiol. 1988;54(6):1341-4.

64. Warburton PJ, Amodeo N, Roberts AP. Mosaic tetracycline resistance genes encoding ribosomal protection proteins. J Antimicrob Chemother. 2016; 71(12):3333-9.

65. Roberts MC. Update on acquired tetracycline resistance genes. FEMS Microbiol Lett. 2005;245(2):195-203.

66. Wang H, Avican K, Fahlgren A, Erttmann SF, Nuss AM, Dersch P, Fallman M, Edgren T, Wolf-Watz H. Increased plasmid copy number is essential for Yersinia T3SS function and virulence. Science. 2016;353(6298):492-5.

\section{Publisher's Note}

Springer Nature remains neutral with regard to jurisdictional claims in published maps and institutional affiliations. 